\title{
A study of the prevalence and risk factors for cardiovascular disorders among \\ patients registered with the primary health centres in Majmaah, Saudi Arabia
}

\section{Mohammed A. Al Mansour}

Department of Family Medicine, College of Medicine, Majmaah University, Kingdom of Saudi Arabia

\section{RESEARCH}

Please cite this paper as: Al Mansour MA. A study of the prevalence and risk factors for cardiovascular disorders among patients registered with the primary health centres in Majmaah, Saudi Arabia. AMJ 2018;11(3):202-208. https://doi.org/10.21767/AMJ.2018.3357

\section{Corresponding Author:}

Mohammed A. Al Mansour

Department of Family Medicine, College of Medicine, Majmaah University, Kingdom of Saudi Arabia

Email:m.aalmansour@mu.edu.sa

\section{ABSTRACT}

\section{Background}

Cardiovascular disorders (CVDs) are considered among the most common co-morbidities especially in developed countries that are easily preventable by controlling its risk factors and developing a healthy life style.

Aims

To identify the magnitude and risk factors of CVDs among PHC patients in Majmaah, Saudi Arabia.

\section{Methods}

This was an interviewee based cross-sectional study conducted among the patients who were chosen through a one-stage cluster sampling method. Data was collected through a pre - structured close ended questionnaire.

\section{Results}

The study included 397 participants with mean age of $44.5 \pm 13.7$ years. About 22 per cent of the participants had one of the CVDs and hypertension was the most commonly recorded one (20.4 per cent). Statistically significant risk factors associated with CVDs were smoking (Odds ratio -
2.9), DM (OR-2.1) and obesity (OR-3.5). Triglycerides readings were higher among those having CVDs as compared to those who were healthy.

\section{Conclusion}

It was found that one out of five participants were affected with CVDs in spite of their young age. Obesity, smoking, age, diabetes mellitus and elevated blood pressure were the most important predictors.

\section{Key Words}

Cardiovascular disorders, prevalence, risk factors, hypertension, primary health centres

\section{What this study adds:}

\section{What is known about this subject?}

The prevalence of cardiovascular diseases increases with age irrespective of the lifestyle choices among the population.

\section{What new information is offered in this study?}

This study highlights the importance of primary preventive measures at an early age to reduce the risk of CVDs among the younger population.

3. What are the implications for research, policy, or practice?

A cohort study should be done to find the effectiveness of health education and its effect on the incidence of CVDs among the younger population.

\section{Background}

The recent past has shown dynamic, worldwide changes in cardiovascular disease (CVD) mortality, including death from coronary heart disease (CHD), stroke, and other CVDs. Many Western countries recorded a rise in mortality from CVD until the 1960s and 1970s, with substantial declines since those peaks. Other parts of the world have shown different patterns, including high rates of CVD mortality in Eastern Europe that continues to rise and an ominous epidemic of 
CHD and stroke emerging in developing countries. ${ }^{1}$ The World Health Organization (WHO) estimated that 17.5 million people died from CVDs in 2005, representing 30 per cent of all global fatalities. ${ }^{2}$ Cardiovascular Disease (CVD) is the most common cause of death in the UK and includes coronary heart disease (angina/heart attack), stroke (where normal blood supply to part of the brain is cut off, damaging the area affected); mini stroke (known as transient ischemic attack or TIA) and peripheral arterial disease (narrowing of arteries usually in the legs). ${ }^{3}$ Non modifiable and modifiable risk factors can increase the probability of developing CVD. ${ }^{4}$ Cardiovascular disease can be avoided or delayed, but the necessary changes to dietary habits and lifestyle are not practicable in the short term. Randomized trials show that drugs to lower three risk factors-low density lipoprotein (LDL) cholesterol, ${ }^{1}$ blood pressure, ${ }^{5-7}$ and platelet function (with aspirin) $^{8,9}$ reduce the incidence of ischemic heart disease (IHD) events and stroke. Evidence that lowering serum homocysteine (with folic acid) reduces the risk of these diseases is largely observational but still compelling. ${ }^{10,11}$ The causes of these disparities in CVD burden are primarily environmental and likely include differences in CVD risk factors, lifestyle, and the availability and use of primary and secondary preventive services.

This study aims to estimate the prevalence of cardiovascular disease (CVD) in a screening survey in Majmaah city, Riyadh province of Saudi Arabia, and examine its association with lifestyle and other cardiovascular risk factors.

\section{Method}

A facility-based descriptive cross-sectional approach was used to determine the prevalence and risk factors of cardiovascular disorders (CVDs) among primary health care centres attendants in Majmaah city for a period of one year from September 2013 and October 2014. The study was conducted in Majmaah city, which is located in Riyadh province, middle region Saudi Arabia. The city has a population of about 45,000 . The study population was Saudi adults 20-70 years of age attending selected primary health care centres in Majmaah for any reason. Non-Saudi residents and pregnant women were excluded from this study. A one-stage cluster sampling method was used to include the participants as the primary health care centres were framed firstly and four PHC centres were included randomly. In the second phase, the patients visiting these centres were selected using systematic sampling technique by selecting one out of each successive ten patients based on sample proportionate to size (PPS). The health centres which selected by simple random sampling were Alfiha, Hai Almataar, Al Yarmook and Alfaisilia. Total samples of 397 patients were included during the study period with ages ranged from $20-80$ years.

The data were collected through a pretested questionnaire. The questionnaire included socio demographic factors (age, gender, occupation, residence, income and marital status), Medical history for any chronic health problem including the cardiovascular disorders, clinical examination and laboratory investigations. The clinical examination included Body Mass Index (BMI), assessment of arterial blood pressure and measuring waist circumference. The laboratory investigations were measured by a laboratory specialist by using the same machine for all the samples. Tests included total cholesterol, HDL cholesterol, LDL, triglycerides, and fasting glucose. Total cholesterol, HDL cholesterol, and triglycerides were enzymatically measured.

\section{Data analysis}

After data were collected it was revised, coded and fed to statistical software IBM SPSS version 21. Graphs were constructed using Microsoft excel software.

All statistical analysis was done using two tailed tests and alpha error of 0.05 . $P$ value less than or equal to 0.05 was considered to be statistically significant. Descriptive statistics including frequencies and per cent were used to describe the frequency of each response for categorical data. Mean with standard deviation and percentiles distribution were calculated for laboratory investigations. Chi square test/ Mont Carlo exact test and Fishers exact test (if there were many small expected values) were used to test for association between sample characteristics, risk factors and cardiovascular disorders. Simple logistic regression analysis was done to identify the crude effect size for each risk factor on having CVDs while hierarchical multiple logistic regressions was used to identify the adjusted effect size. Mann-Whitney test was used to compare distributions of laboratory findings according to cardiovascular disorder status.

\section{Ethical approval}

The study was approved by the Ethics Committee of the Basic and Health Science Research Center, Majmaah University. A written consent was obtained from all respondents.

\section{Results}

The study included 397 persons with their age ranging from 20 to 80 years and mean age of $44.5 \pm 13.7$ years. There were 197 (49.6 per cent) males. About 24 per cent of the participants were illiterate and 26 per cent were highly 
educated. About 40 per cent of the sample not working and 47.4 per cent had monthly income up to 5000 SR. There was no information on smoking among 88.2 per cent of the participants.

Prevalence of cardiovascular disorders as shown in (Table 1), 20.4 per cent were hypertensive, 3 per cent had coronary artery disease and only 1.5 per cent had history of cerebrovascular accident. About 78 per cent of the sample had none of the cardiovascular disorders and 19.9 per cent had only one of CVDs (hypertension alone) (Figure 1).

On relating cardiovascular disorders with the participants socio-demographic characteristics (Table 2), 54.3 per cent of participants aging above 60 years had at least one of CVDs compared to 6.8 per cent of those aged $20-40$ years with statistical significance. As for education, 30.9 per cent of illiterate participants had CVD compared to 9.7 per cent university graduated persons with significant difference $(P<0.05)$. None working participants recorded the highest rate of CVDs (23.9 per cent) compared to none at the military field. Gender and monthly income were of significance in levels of having CVDs.

Table 3 shows the association of the risk factors with the occurrence of CVDs. Smoking was significant predictor as smokers recorded triple risk of developing CVDs compared to non-smokers after adjusting for age, gender and other predictors (Adjusted OR=2.9; 95 per cent $\mathrm{Cl}: 1.1-8.5$ ). Diabetes mellitus was the second significant predictor as diabetics had doubled risk of having CVDs compared to nondiabetics (adjusted $\mathrm{OR}=2.1$; 95 per cent $\mathrm{Cl}: 1.3-3.6$ ). The third significant risk factor was obesity as obese participants had 3.5 time more risk to develop CVDs than normal weighted individuals (adjusted $\mathrm{OR}=3.5$; 95 per cent $\mathrm{Cl}: 1.3-$ 9.4). Eating fatty food, regular exercises and having metabolic syndrome were insignificant risk factors for developing CVDs after adjusting for age, gender and other predictors.

On relating lipid profile with CVDs it was clear that mean TG level was significantly higher among participants with CVDs than normal participants $(2.2 \mathrm{mg} / \mathrm{dl}$ and $1.8 \mathrm{mg} / \mathrm{dl}$, respectively). All other studied lipids were insignificantly higher among those with CVDs than among normal participant but low-density lipoprotein was lower $(P>0.05$ for all).

\section{Discussion}

Our study has shown the prevalence of risk factors as well as the odds of developing cardiovascular disorders due to their presence. Among the cardiovascular disorders, it was seen that the prevalence of hypertension (20.4 per cent) was the highest, followed by coronary artery disease ( 3 per cent) and then history of cerebrovascular accidents (1.5 per cent). Studies on hypertension in Saudi Arabia by Taha et al., ${ }^{12}$ shows the prevalence to be around 24 per cent, and $\mathrm{Al}$ Nozha et al. ${ }^{13}$ concluded that it was affecting more than one fourth of the adult Saudi population. Other studies also gave similar findings on the prevalence of coronary artery diseases and cerebrovascular disorders. ${ }^{14-16}$

Risk factors associated with cardiovascular diseases are essential markers to predict how susceptible a person can be at a given time. Predominantly such risk factors like socio - demographic characteristics, lifestyle choices, physical activity and addictions play a major role in the development of CVDs. Our analysed data showed that there was a statistically significant higher prevalence of either one or more of the CVDs in the age group more than 60 years $(54.3$ per cent) compared to those aged 20-40 years (6.8 per cent). This age-related increase has been shown in other studies by Charbel et al., ${ }^{17}$ Al-Hamdan et al., ${ }^{18}$ and Saeed. ${ }^{19}$ Furthermore in our result we found that illiterate participants had higher CVDs (23.9 per cent) as compared to those who were university graduates (9.7 per cent). Related studies are vague on this comparison with some saying that there is lack of such evidence ${ }^{20}$ while others have shown some association like our studies. ${ }^{21,22}$ Smoking as a single most important entity for developing cardiovascular diseases is quite known and, in our study, we saw that the odds (Adjusted OR=2.9; 95 per cent $\mathrm{Cl}: 1.1-8.5$ ) triple due to its exposure among the participants. Bassiony ${ }^{23}$ found that smoking is quite prevalent among Saudi population across all age groups and Sabra et al., ${ }^{24}$ showed that 19 per cent of the student participants in their study were smokers. US department of health has written in its document that cigarette smoking causes 2-4 times higher risk of developing cardiovascular diseases. ${ }^{25}$ Also a WHO report has predicted the mortality due to tobacco smoking to increase to 10 million by the year 2020 (Table 4). ${ }^{26}$

Diabetes and obesity are the other risk factors significantly associated with cardiovascular diseases as a strong predictor of its outcome in this study. The odds of developing cardiovascular disorders among diabetics was more than twice those without diabetes and obese persons were 3.5 more likely to develop CVDs than non - obese individuals. One of the several epidemiological studies recommended that being physically active reduces the risk of coronary heart diseases by 30-50 per cent. ${ }^{27}$ Similarly other studies have identified a high BMI as independent risk 
factors for the development of diabetes and hypertension. $^{28,29}$ Serum triglyceride levels have been a significant predictor of the development of cardiovascular diseases. On comparing the serum triglycerides levels among participants with and without CVDs we found that it was significantly higher $(p=0.002)$. Studies have shown that serum concentration of triglycerides more than $2-10 \mathrm{mmol} / \mathrm{I}$ is associated with an increased risk of cardiovascular disease. ${ }^{30}$ Studies in Saudi Arabia support our findings of an increased risk of cardiovascular diseases among population with high triglyceride levels. ${ }^{31-33}$

\section{Conclusion}

At the end of the survey, the researcher found that one out of each five participants had at least one of the coronary heart diseases irrespective of their young age. Elevated blood pressure was the most dominant CVD. Obesity, smoking, age, and being diabetic were the most important ordered predictors. Elevated lipid profiles were of no significant value except for triglycerides which was higher among those with CVDs. The researcher recommend that a wider and more comprehensive survey should be done to identify more about magnitude and predictors of CVDs. Also more attention should be paid to improve the populations' awareness regarding the importance of modifying life style and behaviour to reduce the magnitude of risk factors and CVDs. Also awareness map should cover importance of periodic check-up for chronic health problems for early discovery and controlling before being disembodied.

\section{References}

1. Howson CP, Reddy KS, Ryan TJ, et al, eds. Control of Cardiovascular Disease in Developing Countries: Research, Development, and Institutional Strengthening. Washington, DC: National Academy Press; 1998.

2. Cardiovascular diseases. Geneva: World Health Organization; 2007. World Health Organization.

Available from:
http://www.who.int/mediacentre/factsheets/fs317/en/i ndex.html.

3. Wald NJ, Law MR. A strategy to reduce cardiovascular disease by more than 80\%. BMJ. 2003;326(7404):1419.

4. Hayes L, White M, Unwin N, et al. Patterns of physical activity and relationship with risk markers for cardiovascular disease and diabetes in Indian, Pakistani, Bangladeshi and European adults in a UK population. J Public Health Med. 2002;24(3):170-8.

5. MacMahon S, Peto R, Cutler J, et al. Blood pressure, stroke and coronary heart disease. Part 1: prolonged differences in blood pressure: prospective observational studies corrected for the regression dilution bias. Lancet. 1990;335:765-74.

6. Collins R, Peto R, MacMahon S, et al. Blood pressure, stroke and coronary heart disease. Part 2: short-term reductions in blood pressure: overview of randomised drug trials in their epidemiological context. Lancet. 1990;335:827-38.

7. Antithrombotic Trialists' Collaboration. Collaborative meta-analysis of randomised trials of antiplatelet therapy for prevention of death, myocardial infarction, and stroke in high risk patients. BMJ. 2002;324:71-86.

8. PROGRESS Collaborative Group. Randomised trial of a perindoprilbased blood- ressure-lowering regimen among 6105 individuals with previous stroke or transient ischaemic attack. Lancet. 2001;358:1033-41.

9. Antiplatelet Trialists' Collaboration. Collaborative overview of randomised trials of antiplatelet therapy. I: Prevention of death, myocardial infarction, and stroke by prolonged antiplatelet therapy in various categories of patients. BMJ. 1994;308:81-105.

10. Schnyder G, Roffi M, Pin R, et al. Decreased rate of coronary restenosis after lowering of plasma homocysteine levels. N Engl J Med. 2001;345:1593-600.

11. Wald DS, Law M, Morris JK. Homocysteine and cardiovascular disease: evidence on causality from a meta-analysis. BMJ. 2002;325:1202-6.

12. Kumosani TA, Alama MN, Iyer A. Cardiovascular diseases in Saudi Arabia. Prime Res Med. 2011;1:1-6.

13. Al-Nozha MM, Abdullah $M$, Arafah $M R$, et al. Hypertension in Saudi Arabia. Saudi Med J. 2007;28(1):77-84.

14. Al-Nozha MM, Arafah MR, Al-Mazrou YY, et al. Coronary artery disease in Saudi Arabia. Saudi Med J. 2004;25(9):1165-71.

15. World Health Organization: Fact Sheets, Cardiovascular Diseases.

http://www.who.int/mediacentre/factsheets/fs317/en/i ndex.html (accessed on 14.02.2018)

16. Bener A. The prevalence of hypertension and its associated risk factors in a newly developed country. Saudi Med J. 2004;25:918-922.

17. El Bcheraoui C, Memish ZA, Tuffaha $M$, et al. Hypertension and its associated risk factors in the kingdom of saudi arabia, 2013: a national survey. Int J Hypertens. 2014;2014.

18. Al-Hamdan N, Saeed A, Kutbi A, et al. Characteristics, risk factors, and treatment practices of known adult hypertensive patients in Saudi Arabia. Int J Hypertens. 2010;2010:168739.

19. Saeed AA, Al-Hamdan NA, Bahnassy AA, et al. Prevalence, awareness, treatment, and control of 
hypertension among Saudi adult population: a national survey. Int J Hypertens. 2011;2011:174135.

20. Alwan $H$, Pruijm M, Ponte $B$, et al. Epidemiology of masked and white-coat hypertension: the family-based SKIPOGH study. PloS ONE. 2014;9(3):e92522.

21. Kalantan KA, Mohamed AG, Al-Taweel AA, et al. Hypertension among attendants of primary health care centers in Al-Qassim region, Saudi Arabia. Saudi Med J. 2001;22(11):960-3.

22. Mackenbach JP, Cavelaars $A E$, Kunst $A E$, et al. Socioeconomic inequalities in cardiovascular disease mortality. An international study. Eur Heart J. 2000;21(14):1141-51.

23. Al Hazzaa HM. Prevalence of physical inactivity in Saudi Arabia: a brief review. Saudi Med J. 2009;30.

24. Sabra AA, Taha AZ, Al-Sebiany AM, et al. Coronary heart disease risk factors: prevalence and behavior among male university students in Dammam City, Saudi Arabia. J Egypt Public Health Assoc. 2007;82(1-2):21-42.

25. US Department of Health and Human Services. The health consequences of involuntary exposure to tobacco smoke: a report of the Surgeon General. Atlanta, GA: US Department of Health and Human Services, Centers for Disease Control and Prevention, Coordinating Center for Health Promotion, National Center for Chronic Disease Prevention and Health Promotion, Office on Smoking and Health. 2006 Jun 27;709.

26. WHO. The role of health professionals in tobacco control. Geneva: WHO; 2005. http://www.who.int/tobacco/resources/publications/w ntd/2005/bookletfinal_20april.pdf (accessed on 14.02.2018)

27. Bassuk SS, Manson JE. Epidemiological evidence for the role of physical activity in reducing risk of type 2 diabetes and cardiovascular disease. J Appl Physiol. 2005;99(3):1193-204.

28. Meigs JB, Wilson PW, Fox CS, et al. Body mass index, metabolic syndrome, and risk of type 2 diabetes or cardiovascular disease. J Clin Endocrinol Metab. 2006;91(8):2906-12.

29. Goran MI, Ball GD, Cruz ML. Obesity and risk of type 2 diabetes and cardiovascular disease in children and adolescents. J Clin Endocrinol Metab. 2003;88(4):141727.

30. Nordestgaard BG, Varbo A. Triglycerides and cardiovascular disease. The Lancet. 2014;384(9943):626-35.

31. Al-Hussein FA, Tamimi W, Al Banyan $E$, et al. Cardiometabolic risk among Saudi children and adolescents: Saudi childrens overweight, obesity, and lifestyles (S.Ch.O.O.Ls) study. Ann Saudi Med.
2014;34(1):46-53. doi: 10.5144/0256-4947.2014.46.

32. Al-Kaabba AF, Al-Hamdan NA, El Tahir A, et al. Prevalence and correlates of dyslipidemia among adults in Saudi Arabia: results from a national survey. Open J Endoc Metab Dis. 2012;2(04):89.

33. Abalkhail BA, Shawky S, Ghabrah TM, et al. Hypercholesterolemia and 5-year risk of development of coronary heart disease among university and school workers in Jeddah, Saudi Arabia. Prev Med. 2000;31(4):390-5.

\section{PEER REVIEW}

Not commissioned. Externally peer reviewed.

\section{CONFLICTS OF INTEREST}

No conflict of interest

\section{FUNDING}

None

\section{ETHICS COMMITTEE APPROVAL}

Majmaah Research Institutional Ethics Committee(MRIEC) Approval Number: MRIEC06/BHSRC890/2013 
Table 1: Prevalence of cardiovascular disorders in Primary Health Care Centres' Attendants in Majmaah, Saudi Arabia during the period from 2013 to 2014

\begin{tabular}{|l|l|l|l|}
\hline Cardiovascular disorders & No (397) & \% & Mean Duration (SD) in years \\
\hline Hypertension & 81 & $20.4 \%$ & $7.5(5.6)$ \\
\hline Coronary Artery Disease & 12 & $3.0 \%$ & $7.5(6.5)$ \\
\hline Cerebrovascular accident & 6 & $1.5 \%$ & $3.9(2.5)$ \\
\hline
\end{tabular}

Figure 1: Distribution of number of cardiovascular disorders in Primary Health Care Centres' Attendants in Majmaah, Saudi Arabia during the period from 2013 to 2014

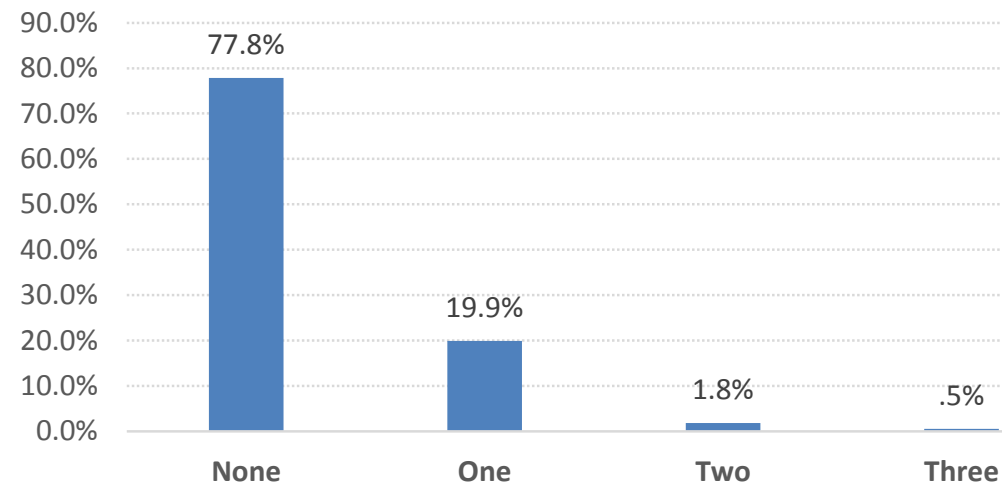

Table 2: Distribution of cardiovascular disorders in Primary Health Care Centres' Attendants in Majmaah by their demographic characteristics, Saudi Arabia during the period from 2013 to 2014

\begin{tabular}{|c|c|c|c|c|c|c|}
\hline \multirow{3}{*}{\multicolumn{2}{|c|}{ Socio-demographic characteristics }} & \multicolumn{4}{|c|}{ Cardiovascular disorders } & \multirow{3}{*}{$\mathbf{P}$} \\
\hline & & \multicolumn{2}{|c|}{ Not present } & \multicolumn{2}{|c|}{ Present } & \\
\hline & & No & $\%$ & No & $\%$ & \\
\hline \multirow{3}{*}{ Age in years } & $20-$ & 123 & $93.20 \%$ & 9 & $6.80 \%$ & \multirow{3}{*}{$0.001^{*}$} \\
\hline & $40-$ & 165 & $75.30 \%$ & 54 & $24.70 \%$ & \\
\hline & $60+$ & 21 & $45.70 \%$ & 25 & $54.30 \%$ & \\
\hline \multirow{2}{*}{$\begin{array}{l}\text { Gender of } \\
\text { Patient }\end{array}$} & Male & 152 & $77.20 \%$ & 45 & $22.80 \%$ & \multirow{2}{*}{0.747} \\
\hline & Female & 157 & $78.50 \%$ & 43 & $21.50 \%$ & \\
\hline \multirow{5}{*}{$\begin{array}{l}\text { Education } \\
\text { Level of } \\
\text { Patient }\end{array}$} & Illiterate & 67 & $69.10 \%$ & 30 & $30.90 \%$ & \multirow{5}{*}{$0.004^{*}$} \\
\hline & Primary & 51 & $72.90 \%$ & 19 & $27.10 \%$ & \\
\hline & Intermediate & 45 & $73.80 \%$ & 16 & $26.20 \%$ & \\
\hline & Secondary & 53 & $80.30 \%$ & 13 & $19.70 \%$ & \\
\hline & University and Above & 93 & $90.30 \%$ & 10 & $9.70 \%$ & \\
\hline \multirow{6}{*}{$\begin{array}{l}\text { Occupation of } \\
\text { Patient }\end{array}$} & Government employee & 109 & $77.90 \%$ & 31 & $22.10 \%$ & \multirow{6}{*}{$0.005^{*}$} \\
\hline & Private employee & 17 & $68.00 \%$ & 8 & $32.00 \%$ & \\
\hline & Military & 9 & $100.00 \%$ & 0 & $0.00 \%$ & \\
\hline & Not working & 121 & $76.10 \%$ & 38 & $23.90 \%$ & \\
\hline & Student & 33 & $100.00 \%$ & 0 & $0.00 \%$ & \\
\hline & Others & 20 & $64.50 \%$ & 11 & $35.50 \%$ & \\
\hline \multirow{4}{*}{$\begin{array}{l}\text { Monthly } \\
\text { Income of } \\
\text { Patients }\end{array}$} & $<5000$ & 141 & $75.00 \%$ & 47 & $25.00 \%$ & \multirow{4}{*}{0.526} \\
\hline & $5000-10,000$ & 97 & $82.20 \%$ & 21 & $17.80 \%$ & \\
\hline & $10,001-15,000$ & 65 & $78.30 \%$ & 18 & $21.70 \%$ & \\
\hline & $>15,000$ & 6 & $75.00 \%$ & 2 & $25.00 \%$ & \\
\hline
\end{tabular}

$* P<0.05$ (significant) 
Table 3: Risk factors of having cardiovascular disorders in Primary Health Care Centres' Attendants in Majmaah, Saudi Arabia during the period from 2013 to 2014

\begin{tabular}{|c|c|c|c|c|c|c|c|}
\hline \multirow{3}{*}{\multicolumn{2}{|c|}{ Risk factors }} & \multicolumn{4}{|c|}{ Cardiovascular disorders } & \multirow{4}{*}{$\begin{array}{c}\begin{array}{c}\text { Crude OR (95\% } \\
\text { CI) }\end{array} \\
3.4(1.2-9.7)^{*}\end{array}$} & \multirow{4}{*}{$\begin{array}{l}\begin{array}{c}\text { Adjusted OR (95\% } \\
\mathrm{Cl})^{\#}\end{array} \\
2.9(1.1-8.5)^{*}\end{array}$} \\
\hline & & \multicolumn{2}{|c|}{ Not present } & \multicolumn{2}{|c|}{ Present } & & \\
\hline & & No & $\%$ & No & $\%$ & & \\
\hline Smoking & $\begin{array}{l}\text { No } \\
\text { Yes }\end{array}$ & $\begin{array}{l}43 \\
266\end{array}$ & $\begin{array}{l}91.50 \% \\
76.00 \%\end{array}$ & $\begin{array}{l}4 \\
84\end{array}$ & $\begin{array}{l}8.50 \% \\
24.00 \%\end{array}$ & & \\
\hline $\begin{array}{l}\text { Regular physical } \\
\text { activity }\end{array}$ & $\begin{array}{l}\text { No } \\
\text { Yes }\end{array}$ & $\begin{array}{l}230 \\
79\end{array}$ & $\begin{array}{l}76.90 \% \\
80.60 \%\end{array}$ & $\begin{array}{l}69 \\
19\end{array}$ & $\begin{array}{l}23.10 \% \\
19.40 \%\end{array}$ & $0.80(0.45-1.41)$ & $0.83(0.46-1.50)$ \\
\hline Eat fatty foods & $\begin{array}{l}\text { No } \\
\text { Yes } \\
\end{array}$ & $\begin{array}{l}270 \\
39 \\
\end{array}$ & $\begin{array}{l}78.50 \% \\
73.60 \% \\
\end{array}$ & $\begin{array}{l}74 \\
14 \\
\end{array}$ & $\begin{array}{l}21.50 \% \\
26.40 \% \\
\end{array}$ & $1.3(0.68-2.54)$ & $1.5(0.73-2.99)$ \\
\hline Diabetes mellitus & $\begin{array}{l}\text { No } \\
\text { Yes }\end{array}$ & $\begin{array}{l}214 \\
95\end{array}$ & $\begin{array}{l}83.90 \% \\
66.90 \% \\
\end{array}$ & $\begin{array}{l}41 \\
47\end{array}$ & $\begin{array}{l}16.10 \% \\
33.10 \% \\
\end{array}$ & $2.6(1.6-4.2)^{*}$ & $2.1(1.3-3.6)^{*}$ \\
\hline Body mass index & $\begin{array}{l}\text { Normal } \\
\text { Overweight } \\
\text { Obese }\end{array}$ & $\begin{array}{l}61 \\
85 \\
163\end{array}$ & $\begin{array}{l}92.40 \% \\
80.20 \% \\
72.40 \%\end{array}$ & $\begin{array}{l}5 \\
21 \\
62\end{array}$ & $\begin{array}{l}7.60 \% \\
19.80 \% \\
27.60 \%\end{array}$ & $\begin{array}{l}1 \\
3.0(1.1-8.4)^{*} \\
4.6(1.8-12.1)^{*}\end{array}$ & $\begin{array}{l}1 \\
2.3(0.79-6.5) \\
3.5(1.3-9.4)^{*}\end{array}$ \\
\hline Metabolic Syndrome & $\begin{array}{l}\text { No } \\
\text { Yes }\end{array}$ & $\begin{array}{l}216 \\
93\end{array}$ & $\begin{array}{l}81.80 \% \\
69.90 \%\end{array}$ & $\begin{array}{l}48 \\
40\end{array}$ & $\begin{array}{l}18.20 \% \\
30.10 \%\end{array}$ & $2.0(1.2-3.1)^{*}$ & $1.5(0.85-2.4)$ \\
\hline
\end{tabular}

OR: Odds ratio

$\mathrm{Cl}$ : Confidence interval

\# OR adjusted for age and gender

Table 4: Distribution of lipid profile in relation to cardiovascular disorders in Primary Health Care Centres' Attendants in Majmaah, Saudi Arabia during the period from 2013 to 2014

\begin{tabular}{|c|c|c|c|c|c|c|c|c|c|}
\hline \multirow{3}{*}{ Lipid profile } & \multicolumn{8}{|c|}{ Cardiovascular disorders } & \multirow{3}{*}{$\mathbf{P}$} \\
\hline & \multicolumn{4}{|c|}{ Not-present } & \multicolumn{4}{|c|}{ Present } & \\
\hline & Mean & SD & $\begin{array}{l}5^{\text {th }} \\
\text { Percentile }\end{array}$ & $\begin{array}{l}95^{\text {th }} \\
\text { Percentile }\end{array}$ & Mean & SD & $\begin{array}{l}5^{\text {th }} \\
\text { Percentile }\end{array}$ & \begin{tabular}{|l|}
$95^{\text {th }}$ \\
Percentile
\end{tabular} & \\
\hline Cholesterol & 4.9 & 1.1 & 3.2 & 6.5 & 5 & 1.2 & 3 & 6.5 & 0.379 \\
\hline $\begin{array}{l}\text { Low density } \\
\text { lipoprotein }\end{array}$ & 3 & 1.4 & 1.3 & 4.6 & 2.8 & 1.3 & 1.1 & 4.5 & 0.366 \\
\hline Triglyceride Level & 1.8 & 0.8 & 0.9 & 3.4 & 2.2 & 1.1 & 1.1 & 3.7 & $0.002^{*}$ \\
\hline $\begin{array}{l}\text { High density } \\
\text { lipoprotein }\end{array}$ & 1.5 & 1.5 & 0.7 & 4.9 & 1.7 & 2.4 & 0.6 & 6 & 0.385 \\
\hline
\end{tabular}

